Article

\title{
Analysis of the Behavior of SMA Mixtures with Different Fillers Through the Semicircular Bend (SCB) Fracture Test
}

\author{
Pedro Limón-Covarrubias ${ }^{1}$, David Avalos Cueva ${ }^{1, * \mathbb{C}}$, Gonzalo Valdés Vidal ${ }^{2}$, \\ Oscar Javier Reyes Ortiz ${ }^{3}$, Rey Omar Adame Hernández ${ }^{4}$ and José Roberto Galaviz González ${ }^{1}$ \\ 1 Department of Civil Engineering and Topography, Guadalajara University, Guadalajara 44430, Mexico; \\ ingenieria_limon@hotmail.com (P.L.-C.); galaviz.gonzalez.r@gmail.com (J.R.G.G.) \\ 2 Department of Civil Engineering, Universidad de La Frontera, Temuco 01145, Chile; \\ gonzalo.valdes@ufrontera.cl \\ 3 Department of Civil Engineering, Nueva Granada Military University, Bogota 49300, Colombia; \\ oscar.reyes@unimilitar.edu.co \\ 4 LASFALTO, Guadalajara, México, 3042 Agua Marina Street, Fracc. Agua Blanca, Zapopan 45236, Mexico; \\ omar.adame@lasfalto.com.mx \\ * Correspondence: david.avalos@academicos.udg.mx; Tel.: +52-331-378-5900 (ext. 27699)
}

Received: 19 October 2018; Accepted: 14 January 2019; Published: 17 January 2019

check for updates

\begin{abstract}
In most cases, stone mastic asphalt (SMA) mixtures placed in thin layers and subjected to stress develop early cracks (potentially resulting from being improperly affixed to the underlying layer, placed over previously cracked asphalt pavement, or placed over Portland cement concrete slabs). However, the filler used in SMA production is very influential on the performance of the mix. Fillers used in this type of mixture have a low plastic index or are inert (calcium carbonate or lime), so it is important to understand the effect of each material on the possible fissuring and cracking process of the SMA mixture. The objective of this study is to present an evaluation of the behavior of SMA asphalt mixtures with different types of filler and at different temperatures using the semicircular bend (SCB) fracture energy test. This research compares results between fracture energy and different types of filler in SMA asphalt mixtures at temperatures ranging from -10 to $25^{\circ} \mathrm{C}$.
\end{abstract}

Keywords: fillers; stone mastic asphalt; semicircular bending; fracture energy; energy index

\section{Introduction}

The main roads are constructed of flexible pavements with asphalt surfaces. However, alternative mixtures, such as stone mastic asphalt (SMA), have been adopted to improve shear strength and durability [1]. Stone mastic asphalts have proven to be reliable because they produce a significant $(20 \%-30 \%)$ increase in stiffness and durability of the pavement compared to conventional mixtures [2]. These mixtures contain discontinuous grain-size distributions and use cellulose, natural and mineral fibers as a stabilizing agent [3], which modifies the mechanical properties of the mixtures [4]. The mixture components include coarse aggregates, a high binder content and a high filler content [2]. The most commonly used fillers are crushed stone, cement and lime [4]; however, recycled materials [5], industrial products, waste materials [6] and even polyethylene terephthalate (PET) have also been used [2].

Based on previous work, Shafiei and Namin [4], evaluated the effect of different percentages of hydrated lime filler (in the dry state and not as an additive) on the performance and mechanical properties of SMAs. They concluded that a percentage greater than $5 \%$ changes the trend and 
reduces rutting indexes. On the other hand, Pereira, Freire, Sá da Costa, Antunes, Quaresma and Micaelo [6] analyzed the ductility of SMAs through strength-ductility tests. For this, they manufactured samples with the same type of paving-grade bitumen but with different types and concentrations of filler. They showed that the ductility is related to the type and concentration of the filler. Finally, Topini, Toraldo, Andena and Mariani [5] revised the compaction properties, volumetric characteristics, and mechanical behavior of SMAs; the mechanical behavior was evaluated with the indirect tensile test at different temperatures. For this, they used two types of recycled material used as filler (stabilized bottom ashes and electric arc furnace steel slag), and their results showed that the behavior of these fillers was similar to or better than that of mixtures with a conventional filler.

Therefore, the objective of this research is to analyze the effect of different fillers (lime, calcium carbonate $\left(\mathrm{CaCO}_{3}\right)$, Filler 1, Filler 2, and Filler 3) on the energy index and fracture energy of SMA mixtures through semicircular bend (SCB) fracture tests at different test temperatures. These tests produced displacement-load graphs of SMAs. Furthermore, the relationship between the test temperature and the fracture energy and energy index was found. Additionally, the physicochemical properties of each filler were evaluated based on the methylene blue value, plasticity index, granulometric composition, scanning electron microscopy analysis, and chemical composition.

\section{Background}

Stone mastic asphalt mixtures were developed in Germany at the end of the 1960s by STRABAG and J. Rettenmaier. Stone mastic asphalts were intended to reduce deterioration, increase useful life and reduce maintenance costs compared to conventional pavements. However, despite their advantages, their use was not normalized in Germany until 1984, when SMAs began to be adopted in other countries in Europe, America and Asia [7,8].

Stone mastic asphalt mixtures are asphalt mixtures characterized by a large amount of coarse aggregate, a high proportion of binder and mineral powder, a low amount of intermediate-size aggregate and a small amount of stabilizing additive. These proportions generate a good mineral structure and a high proportion of filler-based mastic, which enable a high carrying capacity without affecting the flexibility of the mixture $[9,10]$.

The SMA mixtures were conceived with clear and well-defined objectives: To increase the durability, safety and stability of communication routes and to generate savings in their construction. Stone mastic asphalts are hot-prepared mixtures characterized by being impermeable and resistant to the formation of ruts. Arabani and Ferdowsi [11], Erdlen and Yu [7], Guide [9], Kandhal [10], Hainin, Reshi and Niroumand [8], and others have described the advantages of using SMA-type mixtures (Figure 1).

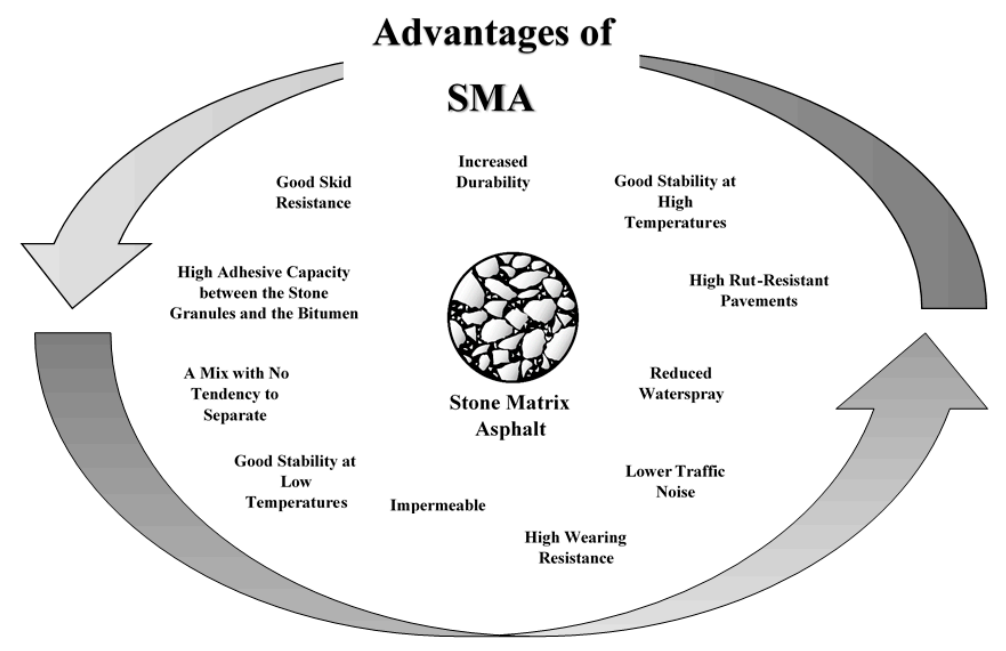

Figure 1. Stone mastic asphalt (SMA) advantages. 
Understanding the propagation of cracks and the time over which deterioration occurs in flexible pavement is the greatest challenge for researchers. Therefore, several modeling schemes exist to discover when and how failure will occur, and understanding these aspects is one of the purposes of this study.

It has been stated that damage due to cracking in an asphalt layer causes the greatest damage, because this is a reflection that some part of the pavement structure has failed [12]. In addition, the passage of vehicles across deteriorated asphalt pavement is uncomfortable for the driver, and in some cases, the repair of damaged pavement is quite expensive. As a result, different laboratory tests have been proposed to mitigate this problem and have suggested a more representative model of asphalt layer deterioration in the field [13-15].

Currently, methods exist to prevent this type of failure, such as the stability and Marshall flow and dynamic and static tests, which attempt to predict the deterioration and durability of an asphalt layer [12,16-18]. Moreover, there are relatively new tests that study fracture energy, which can provide information on the behavior and durability of an asphalt layer, such as the SCB test [11,19-22], which is the test used to evaluate the SMA mixtures in this investigation.

Although there are several methods for the study of asphalt pavement or bearing surface cracking, not all of them satisfy the necessary requirements or can accurately measure the different problems they face. Thus, researchers have crafted methods to develop satisfactory theories and have standardized the problems in laboratory settings $[12,23]$.

The SCB test determines the fracture energy necessary to cause an asphaltic mixture to crack by measuring various physical and/or chemical characteristics and external factors, such as temperature or induced specimen damage.

The SCB test was presented by Kuruppu et al. [24] as a quick 3-point bending test. This test is used to evaluate resistance to fracturing at different temperatures and with different material characteristics, such as different aggregates, asphalt types, asphalt contents and filler types (as in the case of this investigation). In general, the standard procedure is to perform the test at three different temperatures and to compare the results for different compositions. This test uses the finite element method to determine the variation in the load intensity factor with respect to the crack length.

Despite the use of the finite element method to calculate the load with respect to the crack, the fracture energy is still calculated through the experimental results of different tests on the specimens, simply because there are factors that make the test difficult to carry out accurately [25]. For example, a rock particle oriented in the direction of the crack will result in resistance at that point. Thus, it is recommended to test at least six different samples at three different temperatures and loading speeds. The results are directly affected by the type of mixture, which includes the type of stony material, asphalt, and filler. Moreover, another factor that affects the results is the void ratio in each specimen.

Importantly, the SCB test is based on the assumption that the fracture energy is absorbed only by the affected area where the fracture occurs and does not affect the rest of the sample, although recent studies have shown that the entire sample is affected [26,27]. However, this assumption is valid in this test, because the purpose of conducting a test using the SCB method is to measure fracture energy, which means that the goal is only to determine the energy required at different temperatures and loading speeds to produce the fracture.

The SCB test has been used for various purposes, including evaluating the behavior of dense asphalt mixtures with two types of gradations at temperatures of 0 and $25{ }^{\circ} \mathrm{C}$ by Arabani and Ferdowsi [11], assessing different types of asphalt and ages by Kim et al. [28] and measuring the stress intensity factor $\left(\mathrm{K}_{\mathrm{IC}}\right)$ in different types of asphalt and at different test temperatures by Pszczola and Szydlowski [29]. Furthermore, the results derived from the SCB test have been compared with those obtained through the indirect tensile test (IDT) by Kim, Mohammad and Elseifi [28] and the uniaxial tension stress test (UTST) and bending beam test (BBT) by Pszczola and Szydlowski [29], who showed that the SCB test results and the UTST and BBT results showed excellent correlations. 


\section{Materials and Methods}

To fulfill the objective of this research work, the behavior of SMA mixtures manufactured with asphalt PG 70-16 and five different fillers were analyzed. The SMA mixtures were manufactured by combining the asphalt with different fillers (lime, $\mathrm{CaCO}_{3}$, Filler 1, Filler 2, and Filler 3) with a filler/asphalt proportion of 1.51. Additionally, 4 specimens of each SMA mixture were manufactured and tested to obtain an average.

To perform the analysis, it was necessary to determine the characteristics of the aggregates (coarse and fine), the fillers, the asphalt binder, and the SMA mixtures. The specimens were compacted using a Superpave gyratory compactor (Matech, Treviolo, Italy) at 100 gyres with an internal angle of $1.16^{\circ}$ and a stress of $600 \mathrm{kPa}$. Subsequently, the behavior analysis of the different SMA mixtures was conducted via the SCB fracture test at temperatures of $-10,5,15$ and $25^{\circ} \mathrm{C}$. During each test, the load was controlled by displacement at a constant speed of $1 \mathrm{~mm} / \mathrm{min}$.

\subsection{Aggregate Characteristics}

The aggregate used was of basaltic origin and was $100 \%$ produced via crushing. Additionally, two gradations of material were used: Gravel with a maximum size of $19 \mathrm{~mm}$ and sand with a maximum size of $4.75 \mathrm{~mm}$. The sampling of the aggregate material was conducted in accordance with the SCT regulation M-MMP-4-04/02, the characteristics of which are shown in Tables 1 and 2.

Table 1. Characteristics of the coarse aggregate.

\begin{tabular}{lccc}
\hline Characteristic & Normative & $\begin{array}{c}\text { Value } \\
\text { Obtained }\end{array}$ & $\begin{array}{c}\text { Specification } \\
\text { PA-MA-001/2008 }\end{array}$ \\
\hline $\begin{array}{l}\text { Abrasion and Impact in the Los Angeles } \\
\text { Machine, } \%\end{array}$ & ASTM C131-03 & $13 \%$ & $\begin{array}{c}30 \text { max. } \\
\text { (structural layers) }\end{array}$ \\
$\begin{array}{l}\text { Percentage of Fractured Particles in Coarse } \\
\text { Aggregate, } \% \text { (2 faces or more) }\end{array}$ & ASTM D 5821 & $100 \%$ & 90 min. \\
$\begin{array}{l}\text { Elongated Particles in Coarse Aggregate, } \% \\
\text { Flat Particles in Coarse Aggregate, } \%\end{array}$ & ASTM D 4791 & $24 \%$ & 3 a 1\%, 15 max. \\
$\begin{array}{l}\text { Specific Gravity of Coarse Aggregate } \\
\text { Absorption of Coarse Aggregate }\end{array}$ & ASTM D 4791 & $16 \%$ & 3 a 1\%, 15 max. \\
\hline
\end{tabular}

Table 2. Characteristics of the fine aggregate.

\begin{tabular}{lccc}
\hline Test & Normative & $\begin{array}{c}\text { Value } \\
\text { Obtained }\end{array}$ & $\begin{array}{c}\text { Specification } \\
\text { PA-MA-001/2008 }\end{array}$ \\
\hline Equivalent Value of Fine Aggregate, \% & ASTM D 2419 & 61 & $\begin{array}{c}50 \text { min. } \\
\text { (structural layers) } \\
15 \text { max. }\end{array}$ \\
Methylene blue, mg/g & Recommendation & 10 & $\begin{array}{c}\text { (structural layers) } \\
\text { Specific Gravity of Fine Aggregate }\end{array}$ \\
\hline
\end{tabular}

Additionally, the grain size distribution of coarse and fine aggregates is shown in Figure 2. It is evident that the particle size distribution is within the limits established by current regulations. The design was carried out in accordance with the AASHTO MP-8 standard, in which a grain size distribution adjusted to the limits for a nominal maximal size of $9.5 \mathrm{~mm}$ was established. 


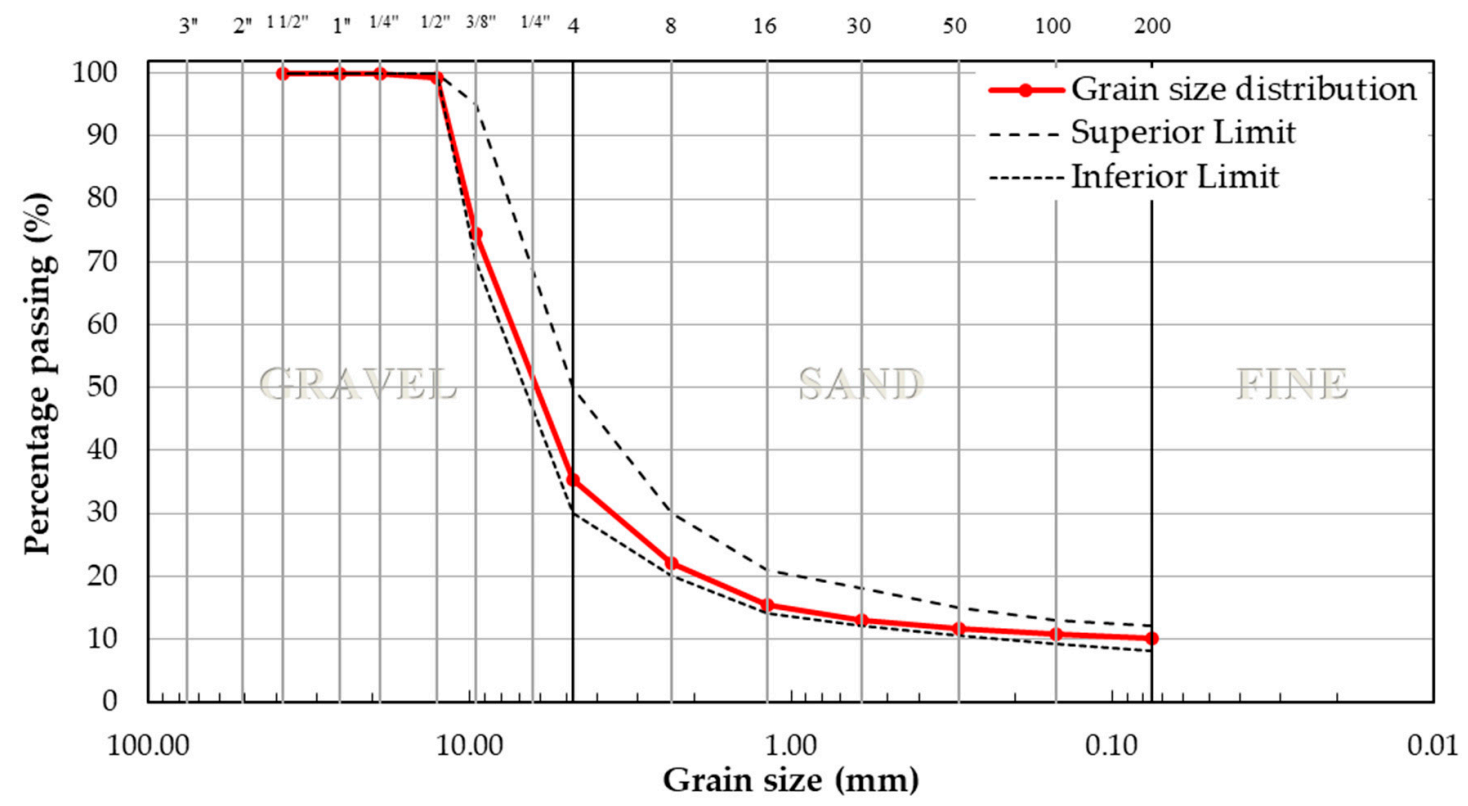

Figure 2. Grain size distribution of aggregates using the AASHTO MP-8 procedure.

\subsection{Physicochemical Properties of Fillers}

In the manufacture of the test SMA mixtures, a 1.51 asphalt/filler proportion was used. Five types of fillers were used for the formation of the test SMA mixtures.

The physicochemical properties of the fillers were analyzed at the Laboratorio de Microscopia de la Universidad Nacional Autónoma de México (see Table 5, Figures 5 and 6). The properties analyzed are as follows:

- Absorption of methylene blue (TC-Technologies, Puebla, Mexico): This test measures the amount of undesirable clay present in the filler; high values $(>13 \mathrm{mg} / \mathrm{g})$ are associated with laminar particles with a large specific surface that react in the presence of water, which activates its expansive potential (deleterious).

- Plasticity index (ALCON, Guadalajara, Mexico): This test assesses the plasticity properties of the clay contained in the filler, and plastic index values greater than 4 are considered unsuitable and associated with laminar-shaped particles.

- Granulometric composition (ALCON, Guadalajara, Mexico): The particle size distribution is obtained, including the percentage of colloidal materials smaller than $0.002 \mathrm{~mm}$, which are considered detrimental due to their expansion potential.

- Analysis by scanning electron microscopy (JEOL USA Inc., Peabody, MA, USA): The micrographs reveal the shapes (equidimensional or laminar) and sizes of the particles; therefore, the results of methylene blue and plasticity index can be verified.

- Chemical analysis (Surfax, Zapopan, Mexico): The aim of this test is to determine the chemical elements contained in each filler.

\subsection{Asphalt Binder Characteristics Used in Test SMA Mixtures}

The optimal asphalt content (AC) was calculated using a Superpave gyratory compactor at 100 gyres, with an internal angle of $1.16^{\circ}$ and a stress of $600 \mathrm{kPa}$. The results of the analysis of the asphalt used in the test SMA mixtures are shown in Table 3. 
Table 3. Asphalt analysis.

\begin{tabular}{ccc}
\hline Binder Analysis & Test & Result \\
\hline & Penetration at $25^{\circ} \mathrm{C} 100 \mathrm{~g} 5 \mathrm{~s}(1 / 10 \mathrm{~mm})$ & 69 \\
& Elastic recovery by torsion at $25{ }^{\circ} \mathrm{C}(\%)$ & 5 \\
Original binder & Softening point at $5{ }^{\circ} \mathrm{C} / \mathrm{min} .\left({ }^{\circ} \mathrm{C}\right)$ & 49 \\
& Performance grade, $\mathrm{PG}$ & 70 \\
& Cleveland flash point & $>260$ \\
& Brookfield viscosity at $135^{\circ} \mathrm{C}$ sc4-27 $12 \mathrm{rpm}(\mathrm{cP})$ & 530 \\
& Module DSR to PG $\left(\mathrm{G}^{*} / \mathrm{sen} \delta\right)(\mathrm{kPa})$ & 1.21 \\
\hline \multirow{3}{*}{ Aged binder RTFO } & Loss mass at $163^{\circ} \mathrm{C}(\%)$ & 0.57 \\
& Performance grade, $\mathrm{PG}$ & 70 \\
& Module DSR to PG $\left(\mathrm{G}^{*} / \mathrm{sen} \delta\right)(\mathrm{kPa})$ & 2.23 \\
\hline \multirow{3}{*}{ Aged binder PAV } & Module DSR at $34{ }^{\circ} \mathrm{C}\left(\mathrm{G}^{*} \operatorname{sen} \delta\right)(\mathrm{kPa})$ & 2102 \\
& Slope $(\mathrm{m}) \mathrm{BBR}$ test at $-6{ }^{\circ} \mathrm{C}$ & 0.312 \\
\hline
\end{tabular}

Additionally, the volumetric properties of the SMA mixtures, such as gravity mixture maximum $\left(G_{\mathrm{mm}}\right)$, gravity mixture bulk $\left(\mathrm{G}_{\mathrm{mb}}\right)$, air voids, voids mineral aggregate (VMA), and voids filled asphalt (VFA), were obtained. These properties are shown in Table 4.

Table 4. Volumetric properties of the SMA mixtures.

\begin{tabular}{ccccccc}
\hline Filler Type & AC (\%) & $\mathbf{G}_{\mathbf{m m}}$ & $\mathbf{G}_{\mathbf{m b}}$ & Air Voids (\%) & VMA (\%) & VFA (\%) \\
\hline Lime & 6.5 & 2.394 & 2.298 & 4.0 & 18.2 & 78.0 \\
$\mathrm{CaCO}_{3}$ & 6.5 & 2.394 & 2.298 & 4.0 & 18.2 & 78.0 \\
Filler 1 & 6.5 & 2.393 & 2.299 & 3.9 & 18.3 & 78.6 \\
Filler 2 & 6.5 & 2.394 & 2.300 & 3.9 & 18.3 & 78.6 \\
Filler 3 & 6.5 & 2.393 & 2.299 & 3.9 & 18.3 & 78.6 \\
\hline
\end{tabular}

\subsection{Semicircular Bend Fracture Test}

The SCB fracture test has been used to obtain the fracture toughness, fracture energy, and stress-softening curves of asphaltic materials. The SCB fracture test is simple to perform and allows one to prepare test specimens easily through Superpave gyratory compactor or field coring. In addition, a mixed-mode fracture can be achieved by modifying the geometry by changing the length (a) and angle of notch $(\alpha)$, as well as the length of the support gap (2s) (see Figure 3a), as mentioned by Ban et al. [30].
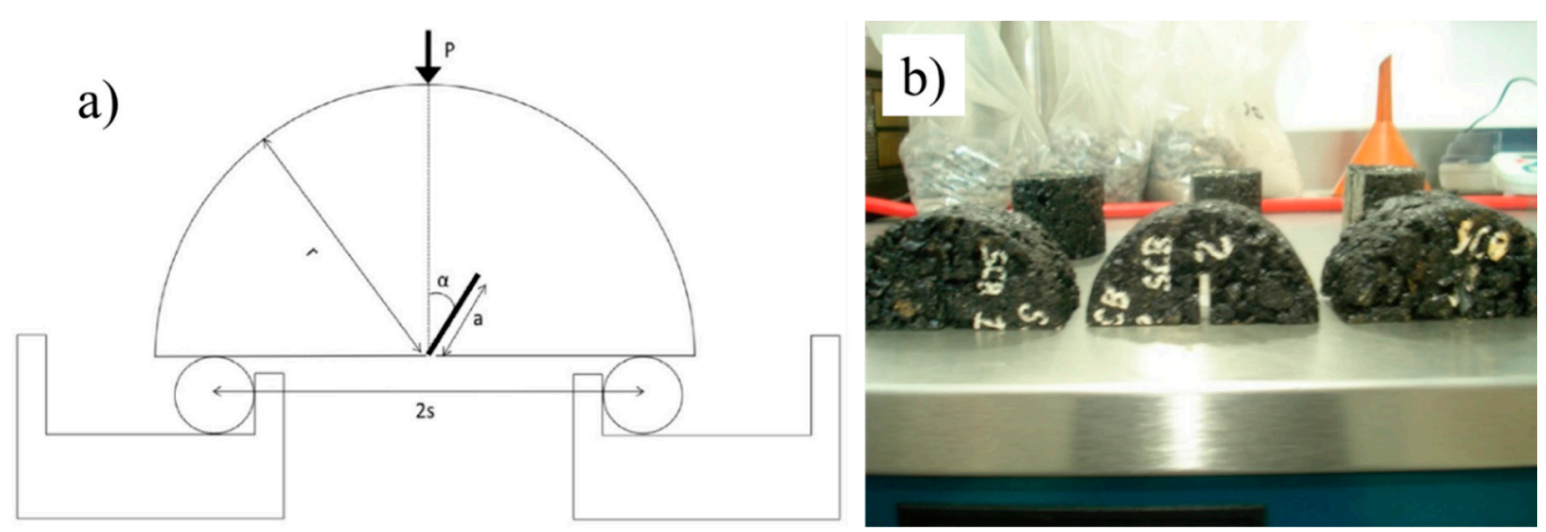

Figure 3. (a) Schematic configuration of the semicircular bend (SCB) test and (b) geometry of the SCB specimens. 
The specimens were made with the same proportions of Asphalt Content (AC), grain size distribution, and type of stone aggregate but had different types of filler. The optimum dosage of filler was determined from calculation to $\mathrm{G}_{\mathrm{mm}}$ and $\mathrm{G}_{\mathrm{mb}}$, as illustrated in Table 4. The specimens were $4 \mathrm{~cm}$ in diameter with a $1 \mathrm{~cm}$ groove depth, and the SCB tests were controlled through Critical tip opening displacement (CTOD) and were performed at a constant loading speed of $1 \mathrm{~mm} / \mathrm{min}$ and at four different temperatures $\left(-10,5,15\right.$ and $\left.25^{\circ} \mathrm{C}\right)$.

Generally, the SCB test yields the stress intensity factor $\left(\mathrm{K}_{\mathrm{IC}}\right)$, critical strain energy $\left(\mathrm{J}_{\mathrm{c}}\right)$ or fracture energy $\left(G_{D}\right)$. However, in the present study, the mechanical properties of the SMAs (see Table 6) were estimated from the expressions (1) to (7) derived from the SCB test and the displacement-load relationship (see Figure 4):

$$
R_{T}=\frac{1000 \times F_{\max }}{h \times l}
$$

where $R_{T}$ is the tensile strength, $F_{\max }$ is the work performed up to the maximum load, $h$ is the specimen thickness and $l$ is the original ligament length.

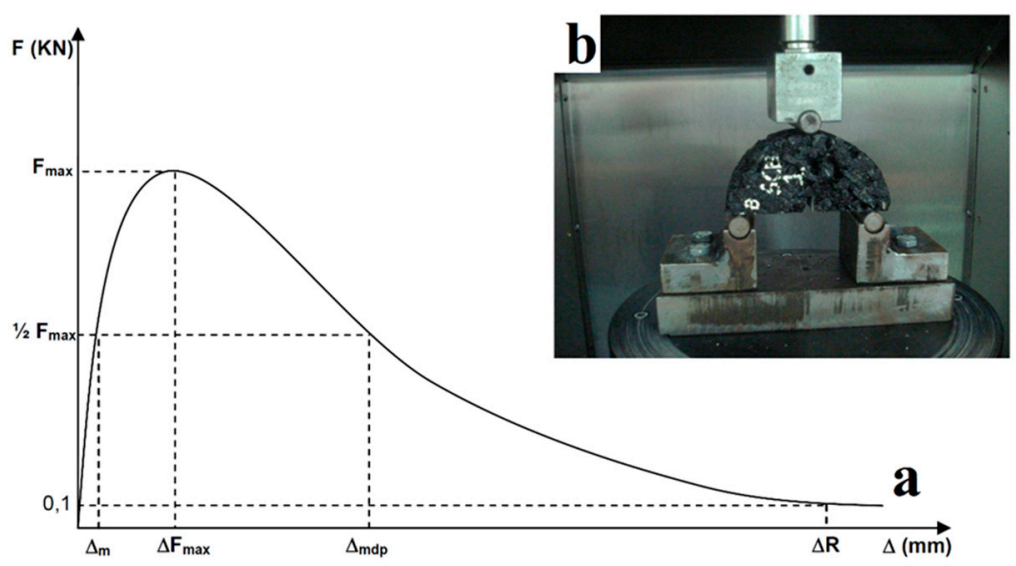

Figure 4. (a) Load-displacement curve and (b) sample used in the test SCB. $W_{D}=$ the work done in the cracking process (F- $\Delta$ area under the load-displacement curve); $W_{F M a x}=$ the work done up to the maximum load (prepeak area); $W_{S}=$ the work done in the softening zone (postpeak area).

The tensile stiffness index $I_{R T}$ is calculated by:

$$
I_{R T}=\frac{\frac{1}{2} \times F_{\max }}{\Delta_{m}}
$$

where $\Delta_{m}$ is the displacement before the maximum load to $\frac{1}{2} F_{\max }$. The calculation of the dissipated energy during cracking $\left(G_{D}\right)$ is determined by:

$$
G_{D}=\frac{W_{D}}{h \times l}
$$

where the work done in the cracking process is calculated $\left(W_{D}\right)$ by:

$$
W_{D}=\sum_{i=1}^{n}\left(x_{i+1}-x_{i}\right) y_{i}+0.5\left(x_{i+1}-x_{i}\right)\left(y_{i+1}-y_{i}\right)
$$

where $x_{i}$ is the displacement recorded, $y_{i}$ is the load recorded and $n$ is the point at which the load decreases to $0.1 \mathrm{kN}$.

The tenacity index $\left(I_{T}\right)$ is obtained by the following equation:

$$
I_{T}=\frac{W_{D}-W_{F \max }}{h \times l}\left(\Delta_{\operatorname{mdp}}-\Delta_{F \max }\right)
$$


where $W_{\text {Fmax }}$ is the work performed up to the maximum load (prepeak area), $\Delta_{m d p}$ is the displacement at $50 \%$ postpeak load, and $\Delta_{\text {Fmax }}$ is the displacement at the maximum load (see Figure 4 ).

The calculation of the energy index $(U)$ is determined by:

$$
U=\frac{W_{S}}{h \times l}\left(\frac{W_{S}}{W_{D}}\right)
$$

where $W_{S}$ is the work done in the postpeak area (softening zone) is determined by:

$$
W_{S}=W_{D}-W_{F \max }
$$

\section{Results and Discussion}

Derived from the physicochemical analysis for different fillers, Table 5 shows that, based on the methylene blue absorption test, Filler 2 and Filler 3 are not suitable for improving SMA mixtures, while lime, $\mathrm{CaCO}_{3}$ and Filler 1 presented methylene blue values of less than $5 \mathrm{mg} / \mathrm{g}$. Therefore, these SMA mixtures will have a better performance, according to the recommendation AMAAC RA-05 [31].

\begin{tabular}{|c|c|c|c|c|c|}
\hline Filler Type & $\begin{array}{l}\text { Methylene Blue } \\
\text { Value (mg/g) }\end{array}$ & $\begin{array}{c}\text { Performance } \\
\text { Recommendation } \\
\text { AMAAC RA-05 }\end{array}$ & $\begin{array}{l}\text { Plasticity } \\
\text { Index (\%) }\end{array}$ & $\begin{array}{c}\text { Early } \\
\text { Performance }\end{array}$ & $\begin{array}{c}\text { Potential of } \\
\text { Hydrogen, } \mathrm{pH}\end{array}$ \\
\hline Lime & 1 & Excellent & No plasticity & No plasticity & 12.80 \\
\hline $\mathrm{CaCO}_{3}$ & 3 & Excellent & No plasticity & No plasticity & 11.60 \\
\hline Filler 1 & 4 & Excellent & No plasticity & No plasticity & 10.60 \\
\hline Filler 2 & 17 & $\begin{array}{l}\text { Problems/possible } \\
\text { failure }\end{array}$ & 5.20 & $\begin{array}{l}\text { Medium } \\
\text { plasticity }\end{array}$ & 9.30 \\
\hline Filler 3 & 32 & Failed & 9.40 & High plasticity & 7.50 \\
\hline
\end{tabular}

Table 5. Methylene blue absorption, plasticity index, and $\mathrm{pH}$ values of analyzed fillers.

Additionally, the plasticity index shown in Table 5 also shows that lime, $\mathrm{CaCO}_{3}$ and Filler 1 do not exhibit plasticity; therefore, they are recommendable for use in SMA mixtures. In contrast, Filler 2 and Filler 3 present medium to high plasticity indexes; therefore, these fillers should not be used.

However, analysis of the granulometric composition of the different fillers revealed that the industrial-product fillers (lime and $\mathrm{CaCO}_{3}$ ) are composed mostly of finer particles and have discontinuous grain size distributions, particularly the lime filler. Meanwhile, the material with the most continuous grain size distribution is Filler 1 (see Figure 5).

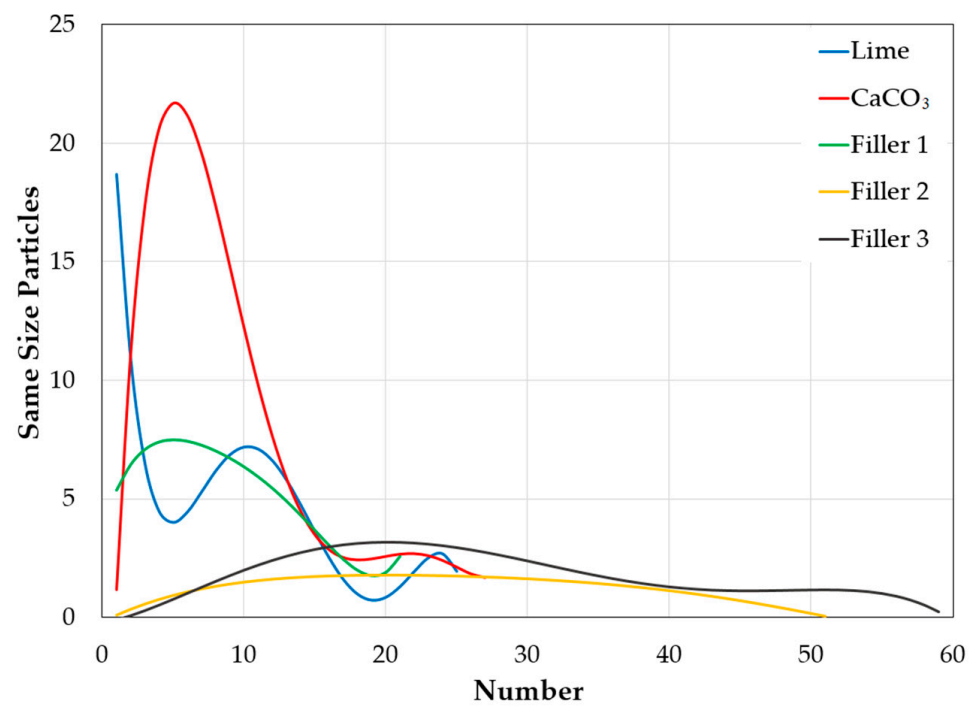

Figure 5. Granulometric composition of lime, $\mathrm{CaCO}_{3}$, Filler 1, Filler 2, and Filler 3. 
Figure 6 shows that the particles of the industrial-product fillers (lime and $\mathrm{CaCO}_{3}$ ) have rounded shapes (Figure 6a,b). Additionally, Figure 6c,d shows that the particles of Filler 1 and Filler 2 are cubic in shape, whereas Filler 3 tends to exhibit needle-like or laminar forms (Figure 6e).
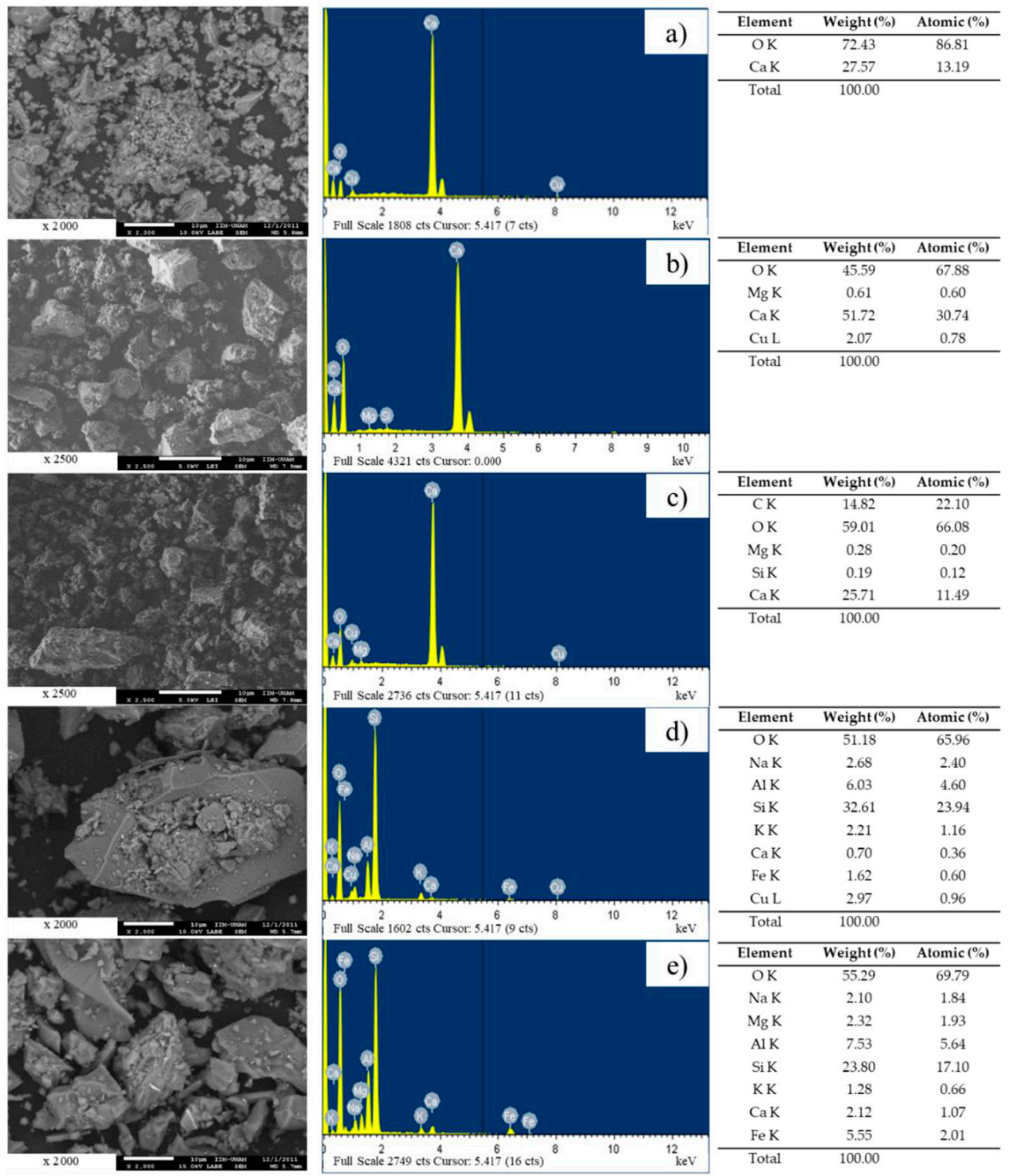

Figure 6. Scanning electron microscopy images of (a) lime; (b) $\mathrm{CaCO}_{3}$; (c) Filler 1; (d) Filler 2 and (e) Filler 3 .

The chemical compositions of the industrial-origin fillers are characterized primarily by oxygen and calcium. In contrast, the crushed rock fillers have more chemical elements; specifically, Filler 3 presents a high combination of aluminum and silicon, which is characteristic of clay materials (Figure 6).

Figure $7 \mathrm{a}$ (according to the SCB test at $-10^{\circ} \mathrm{C}$ ) allows determination of which SMA mixture requires greater fracture energy, because deterioration from thermal cracking can occur under these temperature conditions. 

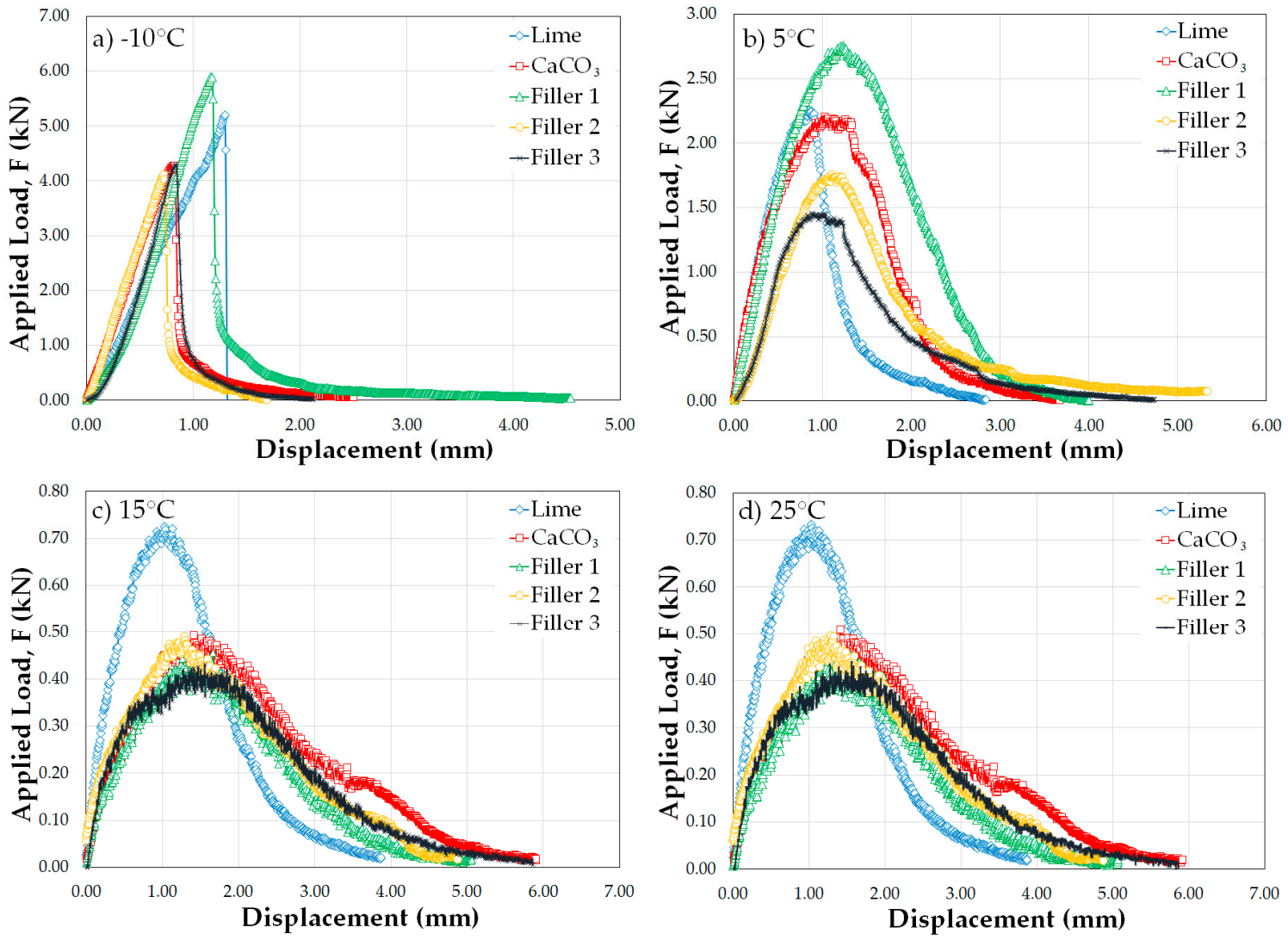

Figure 7. Semicircular bend load-displacement graph of all fillers at (a) $-10{ }^{\circ} \mathrm{C}$; (b) $5{ }^{\circ} \mathrm{C}$; (c) $15^{\circ} \mathrm{C}$ and (d) $25{ }^{\circ} \mathrm{C}$.

All results of the SCB test at $-10{ }^{\circ} \mathrm{C}$ are shown in Table 6 and Figure 7. It is evident that the SMA mixture with Filler 1 has the highest values, with 1215 and $1540 \mathrm{~J} / \mathrm{m}^{2}$ for the test temperature-deformation energy $(U)$ and test temperature-fracture energy $\left(G_{D}\right)$, respectively. These results imply that this mixture presents the best behavior. Moreover, the lowest values in the test were associated with the SMA mixture with Filler 2; consequently, this mixture is more likely to be fragile (see Table 6).

Furthermore, in the SCB test at $5{ }^{\circ} \mathrm{C}$ (see Figure $7 \mathrm{~b}$ ), the best mixture behavior was presented by Filler 1, registering the highest values of $U, G_{D}$ and $I_{T}$, corresponding to 1099,2379 and $979 \mathrm{~J} / \mathrm{m}^{2}$, respectively. The lowest results were associated with the SMA mixture with lime filler. Therefore, Filler 1 has the greatest flexibility and tenacity at $5^{\circ} \mathrm{C}$, which means that thermal fissures and transition to fatigue cracking are less likely to occur (see Table 6).

Figure $7 \mathrm{c}\left(\mathrm{SCB}\right.$ test at $15^{\circ} \mathrm{C}$ ) clearly shows that the SMA mixture tends to exhibit a viscoelastic response due to the rheological properties of the asphalt. In this test, the best behavior is recorded with the mixture containing Filler 1, with values of 241,494 and $182 \mathrm{~J} / \mathrm{m}^{2}$ for $U, G_{D}$ and $I_{T}$, respectively (see Table 6). Therefore, Filler 1 has greater resistance to fatigue cracking that occurs under these temperature conditions. The minimal recorded values correspond to the $\mathrm{CaCO}_{3}$ and lime fillers.

The SCB test results at $25^{\circ} \mathrm{C}$ are shown in Figure 7 and Table 6, and the results of the SCB test are presented. The highest records are recorded in the mixtures with Filler 1 (values of 309, 762 and $484 \mathrm{~J} / \mathrm{m}^{2}$ for $U, G_{D}$ and $I_{T}$, respectively) and $\mathrm{CaCO}_{3}$ (values of 367,832 and $305 \mathrm{~J} / \mathrm{m}^{2}$ for $U, G_{D}$ and $I_{T}$, respectively). The lowest results are for Filler 2, Filler 3 and lime. Therefore, Filler 1 and $\mathrm{CaCO}_{3}$ have the highest flexibility and tenacity at $25{ }^{\circ} \mathrm{C}$, which makes fatigue cracking less likely to occur in these fillers. 
Table 6. The results for all fillers analyzed in the SCB test at $-10{ }^{\circ} \mathrm{C}, 5^{\circ} \mathrm{C}, 15^{\circ} \mathrm{C}$ and $25^{\circ} \mathrm{C}$.

\begin{tabular}{|c|c|c|c|c|c|c|c|c|c|c|c|c|c|c|}
\hline \multirow[b]{2}{*}{ Filler Type } & \multicolumn{7}{|c|}{$-10^{\circ} \mathrm{C}$} & \multicolumn{7}{|c|}{$5{ }^{\circ} \mathrm{C}$} \\
\hline & $\begin{array}{c}\Delta F_{\max } \\
(\mathbf{k N})\end{array}$ & $\begin{array}{l}\Delta F_{\max } \\
(\mathrm{mm})\end{array}$ & $\begin{array}{c}\Delta R \\
(\mathrm{~mm})\end{array}$ & $\begin{array}{c}I_{R T} \\
(\mathrm{kN} / \mathrm{mm})\end{array}$ & $\underset{\left(J / m^{2}\right)}{U}$ & $\begin{array}{c}G_{D} \\
\left(\mathrm{~J} / \mathrm{m}^{2}\right)\end{array}$ & $\begin{array}{c}I_{T} \\
\left(\mathrm{~J} / \mathrm{m}^{2}\right)\end{array}$ & $\begin{array}{c}\Delta F_{\max } \\
(\mathbf{k N})\end{array}$ & $\begin{array}{l}\Delta F_{\max } \\
(\mathrm{mm})\end{array}$ & $\begin{array}{c}\Delta R \\
(\mathrm{~mm})\end{array}$ & $\begin{array}{c}I_{R T} \\
(\mathrm{kN} / \mathrm{mm})\end{array}$ & $\underset{\left(J / m^{2}\right)}{U}$ & $\begin{array}{c}G_{D} \\
\left(\mathrm{~J} / \mathrm{m}^{2}\right)\end{array}$ & $\begin{array}{c}I_{T} \\
\left(\mathrm{~J} / \mathrm{m}^{2}\right)\end{array}$ \\
\hline Lime & 4.72 & 0.95 & 0.95 & 5.59 & 1146 & 1176 & n.a. & 2.30 & 0.83 & 2.17 & 3.93 & 588 & 1109 & 190 \\
\hline $\mathrm{CaCO}_{3}$ & 4.27 & 0.69 & 1.35 & 7.13 & 753 & 914 & n.a. & 2.28 & 1.14 & 2.89 & 3.11 & 860 & 1699 & 487 \\
\hline Filler 1 & 4.91 & 0.99 & 2.46 & 5.70 & 1215 & 1540 & n.a. & 2.85 & 1.28 & 3.46 & 2.95 & 1099 & 2379 & 979 \\
\hline Filler 2 & 4.44 & 0.74 & 0.94 & 6.13 & 738 & 855 & n.a. & 2.39 & 1.06 & 2.66 & 3.20 & 782 & 1559 & 344 \\
\hline Filler 3 & 4.63 & 0.85 & 0.78 & 5.97 & 847 & 949 & n.a. & 1.83 & 1.04 & 2.61 & 3.06 & 605 & 1249 & 403 \\
\hline \multirow[b]{2}{*}{ Filler Type } & \multicolumn{7}{|c|}{$15^{\circ} \mathrm{C}$} & \multicolumn{7}{|c|}{$25^{\circ} \mathrm{C}$} \\
\hline & $\begin{array}{c}\Delta F_{\max } \\
(\mathbf{k N})\end{array}$ & $\begin{array}{l}\Delta F_{\max } \\
(\mathrm{mm})\end{array}$ & $\begin{array}{c}\Delta R \\
(\mathrm{~mm})\end{array}$ & $\begin{array}{c}I_{R T} \\
(\mathrm{kN} / \mathrm{mm})\end{array}$ & $\underset{\left(\mathrm{J} / \mathrm{m}^{2}\right)}{U}$ & $\begin{array}{c}G_{D} \\
\left(\mathrm{~J} / \mathrm{m}^{2}\right)\end{array}$ & $\begin{array}{c}I_{T} \\
\left(\mathrm{~J} / \mathrm{m}^{2}\right)\end{array}$ & $\begin{array}{c}\Delta F_{\max } \\
(\mathbf{k N})\end{array}$ & $\begin{array}{l}\Delta F_{\max } \\
(\mathrm{mm})\end{array}$ & $\begin{array}{c}\Delta R \\
(\mathrm{~mm})\end{array}$ & $\begin{array}{c}I_{R T} \\
(\mathrm{kN} / \mathrm{mm})\end{array}$ & $\underset{\left(J / m^{2}\right)}{U}$ & $\begin{array}{c}G_{D} \\
\left(\mathrm{~J} / \mathrm{m}^{2}\right)\end{array}$ & $\begin{array}{c}I_{T} \\
\left(\mathrm{~J} / \mathrm{m}^{2}\right)\end{array}$ \\
\hline Lime & 0.74 & 0.58 & 1.18 & 2.33 & 146 & 286 & 56 & 0.76 & 0.87 & 2.40 & 1.43 & 204 & 526 & 159 \\
\hline $\mathrm{CaCO}_{3}$ & 0.31 & 0.78 & 1.49 & 1.55 & 81 & 170 & 58 & 0.62 & 1.80 & 4.37 & 0.48 & 367 & 832 & 305 \\
\hline Filler 1 & 0.66 & 1.05 & 2.37 & 1.65 & 241 & 494 & 182 & 0.60 & 1.63 & 3.91 & 0.64 & 309 & 762 & 484 \\
\hline Filler 2 & 0.62 & 0.71 & 1.76 & 2.16 & 153 & 363 & 130 & 0.60 & 1.25 & 3.17 & 0.74 & 258 & 650 & 287 \\
\hline Filler 3 & 0.58 & 0.85 & 1.69 & 1.63 & 170 & 328 & 87 & 0.60 & 1.67 & 3.81 & 0.60 & 285 & 668 & 323 \\
\hline
\end{tabular}

Note: $F_{\max }=$ maximum load, $\Delta F_{\max }=$ maximum load displacement, $\Delta R=$ break displacement, $I_{R T}=$ stiffness index to $F_{\max }, I_{T}=$ tenacity index, $G_{D}=$ fracture energy, and $U=$ index energy. 
According to Table 6, in the SCB test at $-10^{\circ} \mathrm{C}$, it is evident that the SMAs resist forces of greater magnitude that produce little displacement, with which the rigidity indexes $\left(I_{R T}\right)$ increase and become more fragile; therefore, they have tenacity index $\left(I_{T}\right)$ values of zero. In the tests at $5{ }^{\circ} \mathrm{C}, 15^{\circ} \mathrm{C}$ and $25^{\circ} \mathrm{C}$, the SMAs show increasing tenacity index values, indicating that the mixtures become more resistant to loads and deformation. Based on the above results, Filler 1 presents the highest tenacity index values and is therefore the most tenacious and least fragile SMA mixture; therefore, more energy is required to deform and fracture this SMA mixture.

In Figures 8 and 9, Filler 1 is shown to have greater deformation and fracture energy values at all testing temperatures, which shows that the SMA mixtures with this filler are more resistant to the cracking process. Additionally, the lime filler and Filler 3 tend to show low index energy and fracture energy values at the different temperatures in the SCB test. On the other hand, the $\mathrm{CaCO}_{3}$ filler and Filler 2 present greater variability in the index energy and fracture energy values, which confirms their instability in the thermal cracking and fatigue cracking processes.

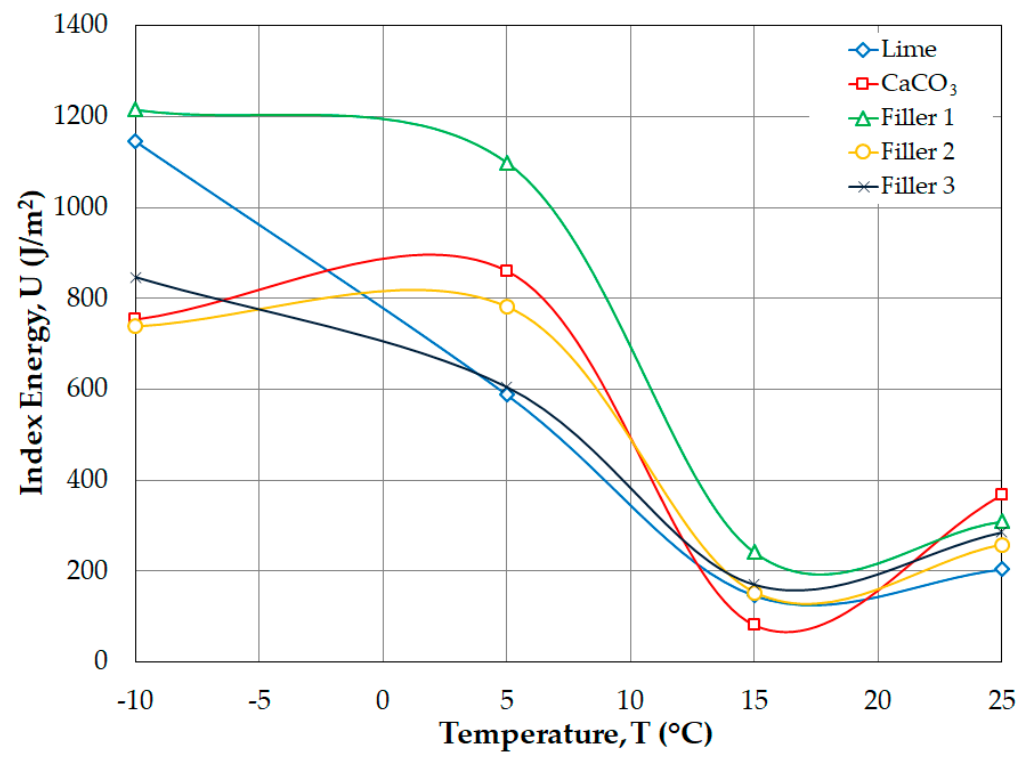

Figure 8. Index energy $(U)$ as a function of test temperature.

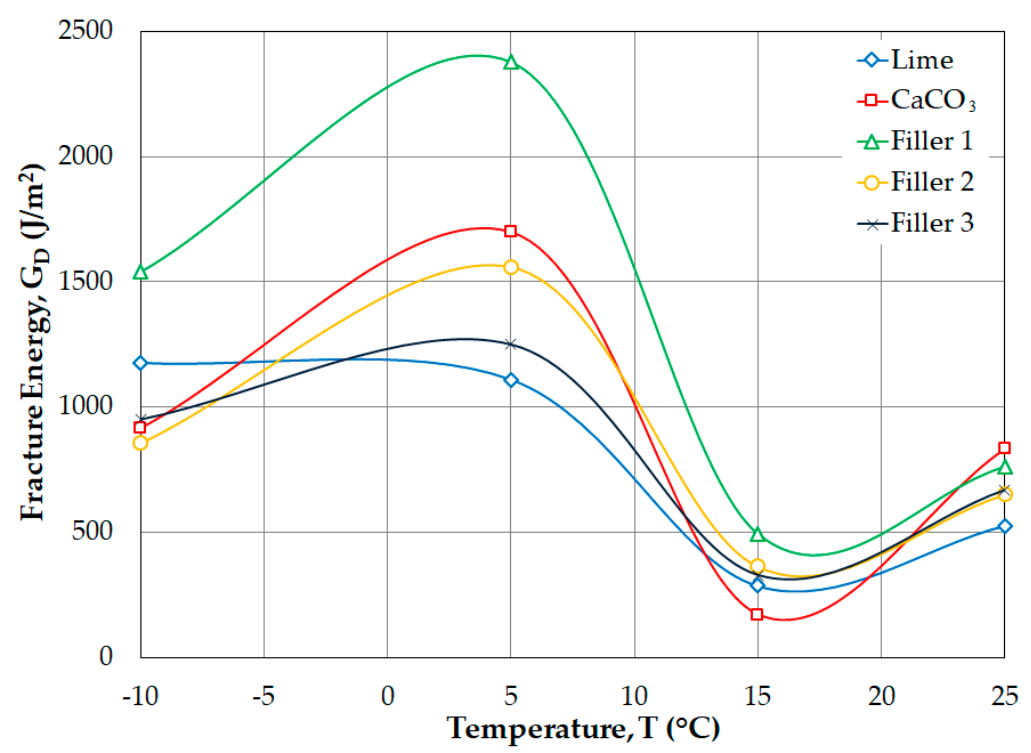

Figure 9. Fracture energy $\left(G_{D}\right)$ as a function of test temperature. 
Consequently, it was determined that Filler 1, derived from crushed rock, has the best behavior in terms of the energy fracture parameters measured through the SCB test, guaranteeing better resistance to possible thermal or fatigue cracking than the other fillers. In addition, the results demonstrated that industrial products (particularly lime) are more susceptible to cracking.

\section{Conclusions}

The aim of this work was to evaluate the effect of fillers on the index energy and fracture energy of SMAs with different fillers. Thus, five different fillers were mixed with one asphalt type at the same filler-to-asphalt ratio and tested using the SCB fracture test. The deformation and fracture energy results were analyzed and related to the displacement-load relationship and physicochemical composition results in terms of filler-asphalt interaction.

The effect of fillers in the displacement-load curves showed that the resistance of the SMA mixtures depends on the test temperature. However, with a temperature of $25^{\circ} \mathrm{C}$ the fracture energy and index energy increase. Analyzing the physical and chemical properties of the fillers, it is evident that the dosage, the shape of the particles and the chemical composition affect the performance of the SMA mixture.

Thus, the best performance of the SMA was obtained with fillers with the lowest proportion of aluminum and silicon (harmful clays components). Likewise, if the filler particles are equidimensional (cubic, spherical or similar), they have a smaller specific surface area, absorb less methylene blue, and have lower plasticity index values. Thus, the reduction of these properties improves the performance of the SMA. For that reason, Filler 1 and lime filler performed better than other fillers at lower temperatures, whereas Filler 1 showed lower performance at intermediate temperatures.

Additionally, the relationship between the temperature-energy index and fracture energy indicates that lower proportions of aluminum and silicon are associated with better performance; therefore, more energy is required to produce deformation and a fracture when Filler 1 is added to the SMA mixture. In contrast, the lime filler presents the worst performance with respect to the energy index and fracture energy.

According to the mechanical properties, Filler 1 presents the highest tenacity index values in all the tests at different temperatures. Therefore, the SMAs mixed with Filler 1 are more tenacious, more ductile and less fragile than the other mixtures; therefore, more energy is required to deform and fracture this SMA mixture. In contrast, the lime filler has the lowest tenacity index values and is therefore the one that presents the most unfavorable behavior.

Importantly, the use of industrial materials such as $\mathrm{CaCO}_{3}$ and lime does not always guarantee good performance of the SMA mixtures in the cracking process, as evidenced by the fillers evaluated with the SCB test in this study.

Author Contributions: Conceptualization, D.A.C., P.L.-C., G.V.V. and O.J.R.O.; Methodology, D.A.C., P.L.-C., G.V.V. and J.R.G.G.; Software, D.A.C., J.R.G.G. and G.V.V.; Validation, R.O.A.H., P.L.-C. and J.R.G.G.; Investigation, D.A.C., P.L.-C. and J.R.G.G.; Resources, D.A.C. and J.R.G.G.; Data Curation, P.L.-C., G.V.V. and R.O.A.H.; Writing-Original Draft Preparation, P.L.-C., D.A.C. and R.O.A.H; Writing-Review \& Editing, P.L.-C., D.A.C. and J.R.G.G.; Supervision, O.J.R.O. and G.V.V.; Project Administration, P.L.-C. and D.A.C.

Funding: This research received no external funding.

Acknowledgments: University of Guadalajara and SURFAX Company.

Conflicts of Interest: The authors declare no conflicts of interest.

\section{References}

1. White, G. State of the art: Asphalt for airport pavement surfacing. Int. J. Pavement Res. Technol. 2017, 11, 79-98. [CrossRef]

2. Ahmadinia, E.; Zargar, M.; Karim, M.R.; Abdelaziz, M.; Shafigh, P. Using waste plastic bottles as additive for stone mastic asphalt. Mater. Des. 2011, 32, 4844-4849. [CrossRef] 
3. Brown, E.; Haddock, J.E.; Mallick, R.B.; Lynn, T.A. Development of a Mixture Design Procedure for Stone Matrix Asphalt (SMA); Report; National Center for Asphalt Technology: Auburn, AL, USA, 1997.

4. Shafiei, A.; Namin, M.L. Experimental investigation on the effect of hydrated lime on mechanical properties of SMA. Constr. Build. Mater. 2014, 70, 379-387. [CrossRef]

5. Topini, D.; Toraldo, E.; Andena, L.; Mariani, E. Use of recycled fillers in bituminous mixtures for road pavements. Constr. Build. Mater. 2018, 159, 189-197. [CrossRef]

6. Pereira, L.; Freire, A.C.; Sá da Costa, M.; Antunes, V.; Quaresma, L.; Micaelo, R. Experimental study of the effect of filler on the ductility of filler-bitumen mastics. Constr. Build. Mater. 2018, 189, 1045-1053. [CrossRef]

7. Erdlen, H.; Yu, J. Stone mastic asphalt: Pavement technology for the new millennium. In Proceedings of the 10th Road Engineering Association of Asia and Australasia (REAAA) Conference, Tokyo, Japan, 4-9 September 2000.

8. Hainin, R.; Reshi, W.F.; Niroumand, H. The importance of stone mastic asphalt in construction. EJGE 1995, 2150, 49-56.

9. HMA Pavement Mix Type Selection Guide; Information Series 128; US Department of Transportation-Federal Highway Administration and National Asphalt Pavement (NAPA): Washington, DC, USA, 2001.

10. Kandhal, P.S. Designing and Constructing SMA Mixtures: State of the Practice; National Asphalt Pavement Association: Lanham, MD, USA, 2002.

11. Arabani, M.; Ferdowsi, B. Evaluating the semi-circular bending test for HMA mixtures. Int. J. Eng.-Trans. A Basics 2008, 22, 47-58.

12. Nejad, F.M.; Aflaki, E.; Mohammadi, M. Fatigue behavior of SMA and HMA mixtures. Constr. Build. Mater. 2010, 24, 1158-1165. [CrossRef]

13. Mamlouk, M.; Mobasher, B. Cracking resistance of asphalt rubber mix versus hot-mix asphalt. Road Mater. Pavement Des. 2004, 5, 435-451. [CrossRef]

14. Portillo, O.; Cebon, D. Fracture of Bitumen and Bituminous Mixes. In Proceedings of the Oatley Seminar, Cambridge University Engineering Department, Cambridge, UK, 21 November 2018.

15. Vidal, G.V. Evaluación del Proceso de Fisuración en las Mezclas Bituminosas Mediante el Desarrollo de un nuevo Ensayo Experimental: Ensayo Fénix; Universitat Politècnica de Catalunya: Barcelona, Spain, 2011.

16. Cooley, L., Jr.; Brown, E. Potential of Using Stone Matrix Asphalt (SMA) for Thin Overlays; NCAT Report 03-01; National Center for Asphalt Technology, Auburn University: Auburn, AL, USA, 2003.

17. Cooley, L.A., Jr.; Hurley, G.C. Potential of Using Stone Matrix Asphalt (SMA) in Mississippi; National Center for Asphalt Technology, Auburn University: Auburn, AL, USA, 2004.

18. Vale, A.C.D.; Casagrande, M.D.T.; Soares, J.B. Behavior of natural fiber in stone matrix asphalt mixtures using two design methods. J. Mater. Civ. Eng. 2013, 26, 457-465. [CrossRef]

19. Al-Qadi, I.L.; Wang, H.; Baek, J.; Leng, Z.; Doyen, M.; Gillen, S. Effects of Curing Time and Reheating on Performance of Warm Stone-Matrix Asphalt. J. Mater. Civ. Eng. 2012, 24, 1422-1428. [CrossRef]

20. Li, X.; Marasteanu, M. Evaluation of the low temperature fracture resistance of asphalt mixtures using the semi circular bend test (with discussion). J. Assoc. Asph. Paving Technol. 2004, 73, 401-426.

21. Monney, O.K.; Khalid, H.A.; Artamendi, I. Assessment of fracture properties of emulsified asphalt mixtures. Road Mater. Pavement Des. 2007, 8, 87-102. [CrossRef]

22. Wu, Z.; Mohammad, L.N.; Wang, L.; Mull, M.A. Fracture resistance characterization of superpave mixtures using the semi-circular bending test. J. ASTM Int. 2005, 2, 1-15. [CrossRef]

23. Medani, T.; Molenaar, A. Estimation of fatique characteristics of asphaltic mixes using simple tests. Heron-Engl. Ed. 2000, 45, 155-166.

24. Kuruppu, M.D.; Obara, Y.; Ayatollahi, M.R.; Chong, K.P.; Funatsu, T. ISRM-suggested method for determining the mode I static fracture toughness using semi-circular bend specimen. Rock Mech. Rock Eng. 2014, 47, 267-274. [CrossRef]

25. Kim, H.; Buttlar, W.G. Discrete fracture modeling of asphalt concrete. Int. J. Solids Struct. 2009, 46, $2593-2604$. [CrossRef]

26. Loizos, A.; Partl, M.N.; Scarpas, T.; Al-Qadi, I.L. Modeling of top-down cracking (TDC) propagation in asphalt concrete pavements using fracture mechanics theory. Adv. Test. Charact. Bitum. Mater. II 2009, 713-724.

27. Huang, L.; Cao, K.; Zeng, M. Evaluation of semicircular bending test for determining tensile strength and stiffness modulus of asphalt mixtures. J. Test. Eval. 2009, 37, 122-128. 
28. Kim, M.; Mohammad, L.N.; Elseifi, M.A. Characterization of fracture properties of asphalt mixtures as measured by semicircular bend test and indirect tension test. Transp. Res. Rec. 2012, 2296, 115-124. [CrossRef]

29. Pszczola, M.; Szydlowski, C. Influence of Bitumen Type and Asphalt Mixture Composition on Low-Temperature Strength Properties According to Various Test Methods. Materials 2018, 11, 2118. [CrossRef]

30. Ban, H.; Im, S.; Kim, Y.-R. Mixed-mode fracture characterization of fine aggregate mixtures using semicircular bend fracture test and extended finite element modeling. Constr. Build. Mater. 2015, 101, 721-729. [CrossRef]

31. Asociación Mexicana del Asfalto, A.C. RECOMENDACIÓN AMAAC. In Determinación del Valor de Azul de Metileno Para Filler y Finos; Instituto Mexicano del Transporte: Ciudad de Mexico, Mexico, 2010; Volume RA 05/2010.

(C) 2019 by the authors. Licensee MDPI, Basel, Switzerland. This article is an open access article distributed under the terms and conditions of the Creative Commons Attribution (CC BY) license (http://creativecommons.org/licenses/by/4.0/). 